DOI: $10.1515 / \mathrm{amm}-2016-0097$

A. NEIMITZ*,\#, U. JANUS*

\title{
ANALYSIS OF STRESS AND STRAIN FIELDS IN AND AROUND INCLUSIONS OF VARIOUS SHAPES IN A CYLINDRICAL SPECIMEN LOADED IN TENSION.
}

\begin{abstract}
A numerical analysis is performed of the stress field in and around inclusions of various shapes. Inclusions both stiffer and more compliant than the metal matrix are analysed. The critical stresses required for inclusion fracture are estimated after observation of cavities and inclusions by scanning electron microscopy. Real inclusions were observed after performing uniaxial loading to different amounts of overall strain. The material tested was Hardox-400 steel.

Keywords: void nucleation, inclusion fracture, critical stress.
\end{abstract}

\section{Introduction}

Both ductile and cleavage failure processes usually initiate by the nucleation of voids or microcracks. They can originate from second-phase particles such as inclusions (e.g., manganese sulphide, MnS) and/or interstitials (e.g., carbides). This first stage is likely common to multiple types of ultimate failure. Whether the failure mechanism exhibits primarily ductile or cleavage character, depends on the levels of the hydrostatic stresses, stress triaxiality, plastic strain and other characteristics of the stress and strain fields. When the mechanical fields favour ductile failure, the nucleus grows as a void. When the opening stress is sufficiently large, the nucleus evolves into a micro-, meso- and finally macrocleavage crack.

In the present paper, we concentrate on the nucleation stage only, which in itself is sufficiently complex to warrant study. The process depends on many factors, including crystallographic structure (e.g., BCC, FCC, HCP), microstructural features (e.g., the size and shape of the grains), morphology and volume fraction of the inclusions or interstitials, and the features of the stress and strain fields. Second-phase particles can either fracture or split from the metal matrix by a debonding process. Which of the two mechanisms takes place depends on the size, shape and chemical composition of the failure nucleus.

The numerical analysis of the nucleation stage of failure, as presented in this paper, involves the presence of large plastic deformations. However, the ultimate failure can be either ductile or brittle in character. This type of failure is often observed in BCC materials, among them ferritic steels.

The failure process is characterized by evolution through the following three stages: 1) the nucleation of voids or microcracks, 2) the growth of voids or micro-cracks to mesocracks and 3) a void's coalescence or sudden cleavage crack jump. These processes are the subject of numerous research programs and research reports, and excellent overviews are available [1], [2], [3]. However, the nucleation stage is not as often discussed in the literature for several reasons:

1. Experimental observations are distributed across various alloys. The nucleation of micro-cracks and voids from carbides and nonmetallic inclusions in ferritic steels are less often studied.

2. All three processes: nucleation, growth, and coalescence/ cleavage jump can take place very rapidly in highstrength alloys, and it is difficult to observe the first stage of failure

3. Voids or microcracks do not nucleate at the same time, and observations are often focused on an individual void or on a few voids only; thus, quantitative results are difficult to interpret. This process is inherently a discontinuous one, consisting of a succession of discrete nucleation events. Moreover, microscopic observations are often challenging to interpret because they depend on the quality of polishing, which can smear out the inclusions.

4. Void or microcrack nucleation is a heterogeneous process that takes place either through particle fracture or from interface debonding. Both of these processes are influenced by multiple factors.

There are, however, several experimental observations accepted by most researchers investigating the nucleation process of voids and micro-cracks:

1. The nucleation process starts with the largest particles and becomes energetically less favourable as the size of the particles decreases [1], [3], [4], [5], [6], [7].

2. Larger particles fracture more often than smaller ones. The latter become the kernels of nucleation through the process of debonding from the metal matrix. This can be attributed to the higher likelihood that a larger particle will contain a submicron defect [4].

3. A soft matrix favours particle debonding, whereas a hard matrix favours particle cracking.

\footnotetext{
* KIELCE UNIVERSITY OF TECHNOLOGY,FACULTY OF MECHATRONICS AND MACHINE DESIGN, 1000 LECIA P.P. 7 AV.,25-314 KIELCE, POLAND

* Corresponding author: neimitz@tu.kielce.pl
} 
4. The shape of the particle may determine the mode of nucleation. For example, an oblong particle oriented along the loading direction is more prone to fracture than the same particle oriented perpendicular to the loading direction. In the latter case, nucleation by interface debonding is more likely.

5. Cleavage microcracks and voids are progressively nucleated under the influence of plastic deformation. Some authors claim that the nucleation process arises from the heterogeneity of plastic deformation in the so-called slip-induced process. Other claim that plastic deformation must necessarily accumulate sufficiently at the interface (whose physical interpretation is debateable) to raise the stress above a critical strength level.

Inclusions within metals are generally inhomogeneously present in various shapes, sizes and clusters through the material. Shabrov and Needleman [8] addressed inclusion failure, though their treatment assumed only square inclusion shapes and they analysed the debonding process only. In their study the cohesive model along the inclusion surface was used. The shape, size, morphology of inclusions and stress triaxiality levels were the parameters of the model. Although the analysis consisted of a relatively simple inclusion model, it enabled several interesting qualitative conclusions concerning void nucleation. Among them were: 1) low triaxiality requires more extensive plastic straining, 2) smaller inclusions require higher values of void nucleation strain than larger inclusions, and 3 ) clustering has a significant effect on debonding strain and stress.

For this simple inclusion model, the strain at debonding varied from $0.5 \%$ to $9 \%$. In turn, the effective stress $\sigma_{e}$ was recorded within the range of $\sigma_{e} / \sigma_{0} \in(0.87-1.66)$ ( where $\sigma_{0}$ is the yield stress.

In an additional paper by Shabrov et al. [9], experimental results obtained from 4340 steel were presented along with the results of finite element analysis. In this case, the fracture of titanium-nitride particles was observed. This process took place over a narrow loading range corresponding to the weighted sum of the hydrostatic tension $\sigma_{h}$ and the effective stress $\sigma_{e}$

$$
\begin{aligned}
& \sigma_{e}+c \sigma_{h}=\sigma_{n}=\Sigma_{N} \\
& \text { and } \Sigma_{N} \in[2.3 \div 2.4] \sigma_{0} .
\end{aligned}
$$

Argon and Im [10] were probably the first to propose an equation similar to Eq. (1), though the weighting factor $\mathrm{c}$ was absent. Later, Needleman [11] introduced a correction to the Argon equation. An equation similar to Eq. (1) was developed from a phenomenological analysis based on the Eshelby model [12], which was later further developed by models that incorporated stresses from dislocation pile-up (e.g., Margolin et al. [13]). These equations were expressed in terms of the overall stress measures; they also contained shape functions originating from simple models. It is now possible, in this age of numerical methods, to compute stress and strain fields in and around foreign particles of arbitrary shape and orientation within a metal matrix. Using the set of cohesive models, it is also possible to analyse the debonding process. However, one important problem remains: the field lacks actual values of parameters (e.g., normal stress, plastic strain, effective stress or strain, and energy) that can be used in failure criteria. Those few numbers that can be found in the literature have been obtained for selected materials and for various selected-usually simplisticmodels of defects and materials. The critical stress needed to fracture elongated $\mathrm{MnS}$ inclusions in A508 steel was proposed by Beremin [14] to equal $1100 \mathrm{MPa}$. The same author proposed that the critical $\mathrm{MnS}$ debonding stress is $800 \mathrm{MPa}$. Argon and Im [10] proposed the critical stress to debond a rounded $\mathrm{Fe}_{3} \mathrm{C}$ inclusion to be $1650 \mathrm{MPa}$. The critical stress to fracture $\mathrm{TiN}$ in 4340 steel was proposed by Shabrov et al. [9] to be $2300 \mathrm{MPa}$ and by Alexandre et al. [15] in Inconel 718 to be 1280-1540 MPa; additionally, Mishnayevsky et al. estimated the critical normal stress for $\mathrm{F}_{3} \mathrm{C}$ at $1826 \mathrm{MPa}$. Other critical values are listed in the literature for inclusions in aluminum alloys, pure aluminum and copper alloys. In some investigations, researchers have estimated the critical values of stresses to nucleate voids or microcracks indirectly (e.g., by testing experimentally the ductility of a material). Huber et al. [16] tested the ductility of an Al-Si-Mg alloy and assessed the critical stresses needed to fracture $\mathrm{Si}$ particles is equal to $6.3 \sigma_{0}$ or $2.3 \sigma_{0}$. In turn, Needleman [17] numerically simulated the decohesion process of a "perfect" interface between a viscoplastic material and rigid inclusion and he obtained a decohesion stress in the range of (1.94-7.74) $\sigma_{0}$ as a function of the stress triaxiality. In most of the reports listed above, the critical values are given without additional important information such as the mean particle size and particle size distribution or the flow properties of each phase. In most of the studies, the foreign particles are modelled as spheres. Almost all studies, numerical and experimental, have been carried out using cylindrical specimens or circumferentially notched cylindrical specimens.

TABLE 1

Chemical composition of Hardox-400 steel (\%)

\begin{tabular}{|c|c|c|c|c|c|c|c|c|c|}
\hline \hline & C & Si & Mn & P & S & Cr & Ni & Mo & B \\
\hline Hardox-400 & 0.12 & 0.52 & 1.25 & 0.01 & 0.001 & 0.66 & 0.04 & 0.012 & 0.001 \\
\hline
\end{tabular}

Mechanical properties of Hardox-400 steel (average value of all measured values)

\begin{tabular}{|c|c|c|c|c|}
\hline \hline Temperature $^{\circ} \mathbf{C}$ & $\mathbf{E},(\mathbf{M P a})$ & $\mathbf{R e},(\mathbf{M P a})$ & $\mathbf{R m},(\mathbf{M P a})$ & $\mathbf{A 5}, \mathbf{( \% )}$ \\
\hline+20 & 184 & 953 & 1197 & 15.7 \\
\hline
\end{tabular}




\section{Experimental program}

The material used in this research was Hardox-400. The chemical composition is listed in Table 1 and the uniaxial tensile properties are listed in Table 2 [18].

Nucleation starts much earlier than the stress maximum is observed along the uniaxial strain-stress curve. After nucleation, the strain-stress curve rises as a result of competition between strain hardening and softening from void nucleation and growth. Experimental tests were performed to estimate the value of the overall strain at the moment of void nucleation.

Cylindrical specimens were loaded to three different elongations (see Fig. 1): beyond the external loading maximum, the process was stopped at a strain equal to $1.5 \%$ and $1.0 \%$.

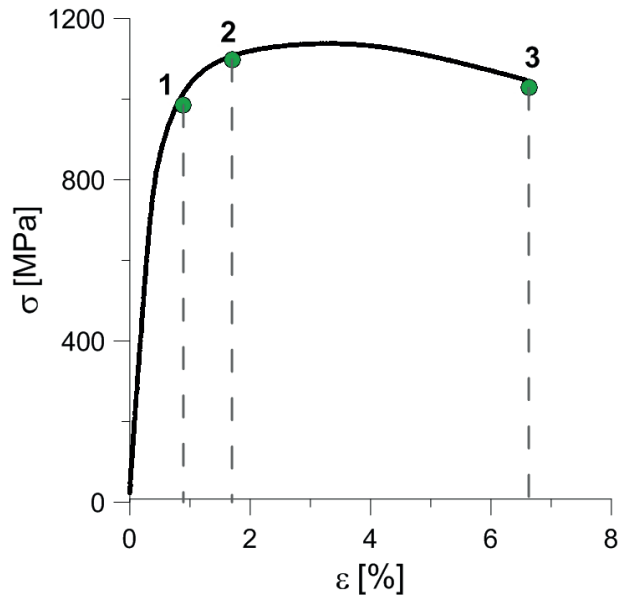

Fig.1. Stress-strain curve obtained in the uniaxial tensile test of the Hardox 400 steel. Vertical lines denote the strains where the tests terminated

The unloaded specimens were cut in a half along their primary axis. They were polished and their microstructure observed using scanning electron microscopy. Microstructure images obtained from the specimens loaded beyond the force maximum revealed numerous voids nucleated through inclusion fracture followed by debonding from the metal matrix. Representative examples are shown in Fig. 2.
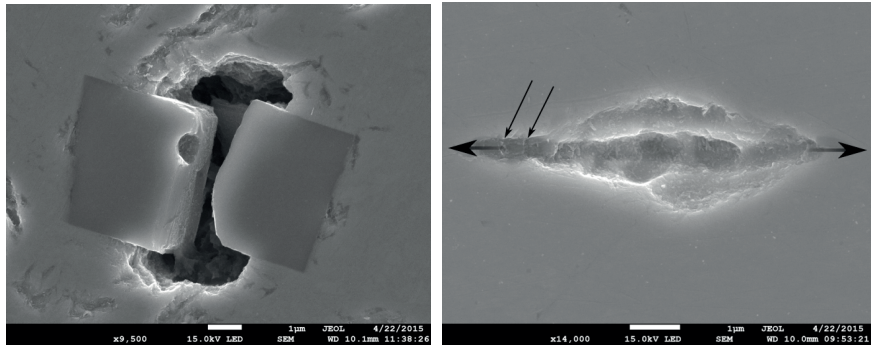

Fig. 2. a) Fracture of a TiN inclusion followed by debonding. b) The remnants of the fractured $\mathrm{MnS}$ inclusion. Large arrows denote the loading direction; small arrows indicate fractured remnants of the $\mathrm{MnS}$ inclusion. The plastic strain was approximately 5\%

Specimens stretched by $1.5 \%$ also reveal both fractured inclusions and voids and inclusions that remain intact (Fig. 3). There are relatively large amounts of nucleated voids (Fig. 3).
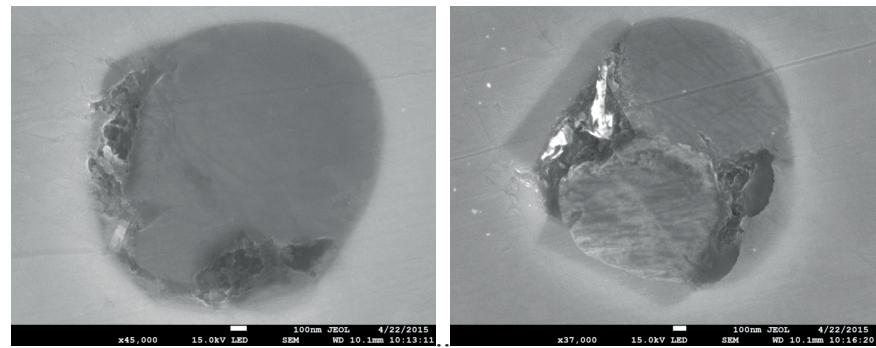

Fig. 3. a) An intact $\mathrm{MnS}$ inclusion and b) nonuniform $\mathrm{MnS}$ inclusion. The fracture process begins with this configuration. Plastic strain: $1.5 \%$
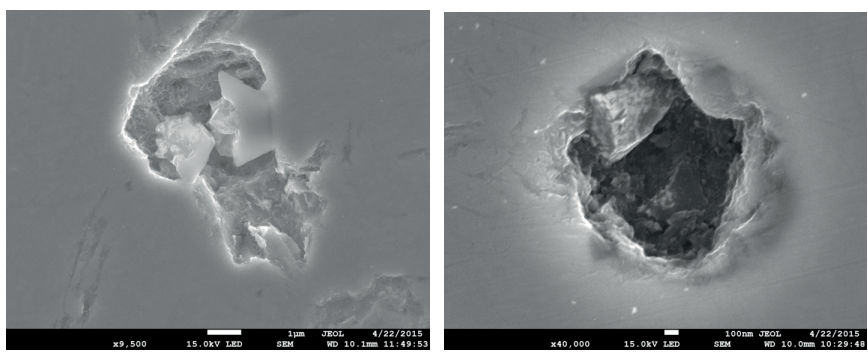

Fig. 3. c) An irregular cavity with the remnants of the fractured TiN inclusion. d) Cavern of a more regular shape with the remnant of an unidentified inclusion. Plastic strain: $1.5 \%$

The specimen that was loaded up to $1 \%$ uniaxial strain exhibited few nucleated voids. Most of the inclusions were intact (see Fig. 4a) and some had already fractured (see Fig. $4 b$ ). However, some had fractured and debonded from the matrix. Debonding could have occurred during polishing. It should be noticed that many of fractured inclusions consisted of several different phases (see Fig. $4 d$ and $4 b$ ).
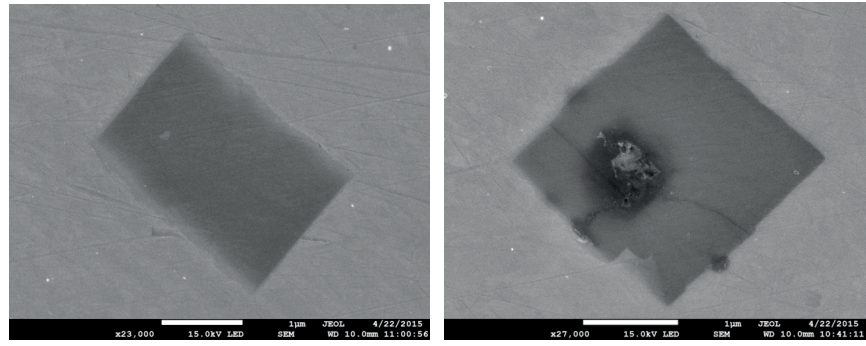

Fig. 4. a) Intact TiN inclusion and b) already-fractured TiN inclusion. Cracks started from the nucleus of the inclusion. Plastic strain: 1\%
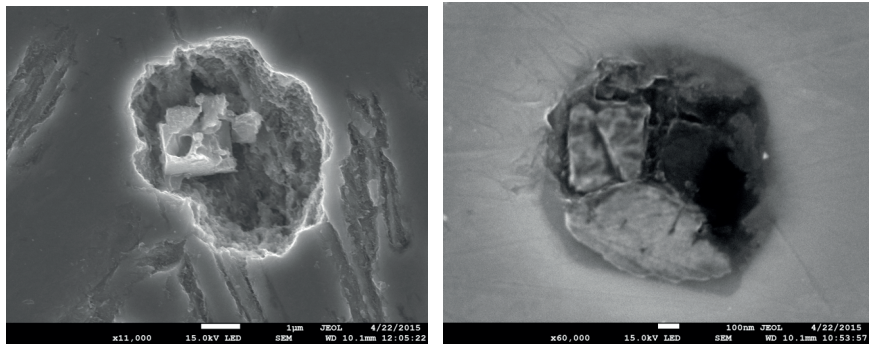

Fig. 4. c) Cavern originating either from debonding or as a result of the polishing process, and d) fractured nonuniform inclusion containing multiple phases. Plastic strain: $1 \%$

Microscopic observations do not allow for a precise statement concerning the level of strain at which an inclusion/ interstitial fractured or debonding took place. This uncertainty 
arises from the variety of inclusion shapes, chemical compositions and inclusion orientations with respect to the external loading direction. Thus, in the finite element method computations, we select the nucleation strain, for the "average" inclusion, to be in the range from $1 \%$ to $3 \%$ of the uniaxial strain.

\section{Numerical model and numerical results}

In this section, a numerical analysis is presented of the stress and strain fields in and around a foreign particle located inside a specimen placed under uniaxial tension. Only the possible nucleation process is analyzed. Elastic particles of various shapes and orientations with respect to the loading direction are located within the elementary volume. The size of the elementary volume was chosen following microscopic observations of Hardox-400 steel. The average distance between the large foreign particles was estimated to be 20 $\mu \mathrm{m}$; this distance is therefore used as the width and height of the elementary cell. In the centre of the elementary cell, the particles with maximum dimensions of $2 \mu \mathrm{m}$ and $0.4 \mu \mathrm{m}$ were located to investigate the influence of particle size on the stress and strain fields.

The value of $u_{n}$ (the displacement applied to the faces of the elementary cell, perpendicular to the loading direction) was taken from experiment at the moment of presumed nucleation.

\subsection{Finite element model of the unit cell in uniaxial ten- sion, axial-symmetrical problem}

The stress state was calculated in and around the inclusion, which was assumed to exist in a cylindrical specimen placed under uniaxial loading. Various inclusion shapes were analyzed (see Fig. 5). The maximum size of the inclusion for each proposed shape was $2 \mu \mathrm{m}$. The aspect ratio (i.e., the ratio of the maximum to minimum size) of the ellipsoidal inclusion (Figs 5a, 5b) and elongated inclusion (Figs $5 \mathrm{~d}, 5 \mathrm{e}$ ) was $\frac{L_{1}}{L_{2}}=4$. The inclusions were located at the centre of the cylindrical unit cell. The axisymmetric problems were solved with a finite element mesh around the inclusion as shown in Fig. 6, for a spherical one. Only a quarter of the unit cell was analyzed because of symmetry. The uniaxial stress-strain relationship of the matrix material (Hardox-400) was recorded experimentally and incorporated into the finite element program. The inclusion material was assumed to be homogeneous, although in many cases we observed inclusions consisting of two or three phases. In most of the simulations it was assumed that the Young's modulus of the inclusions was $300 \mathrm{GPa}$, similar to many typical inclusion materials (e.g., $\mathrm{Al}_{2} \mathrm{O}_{3}, \mathrm{TiN}, \mathrm{MgO}-\mathrm{Al}_{2} \mathrm{O}_{3}, \mathrm{FeS}_{2}, \mathrm{MgO}$ ). Other inclusions as $\mathrm{MnS}$ or $\mathrm{CaS}$ have Young's module lower than the matrix material (from 69 to $130 \mathrm{GPa}$ ). To represent such materials, results are also shown for inclusions that are more compliant than the matrix.

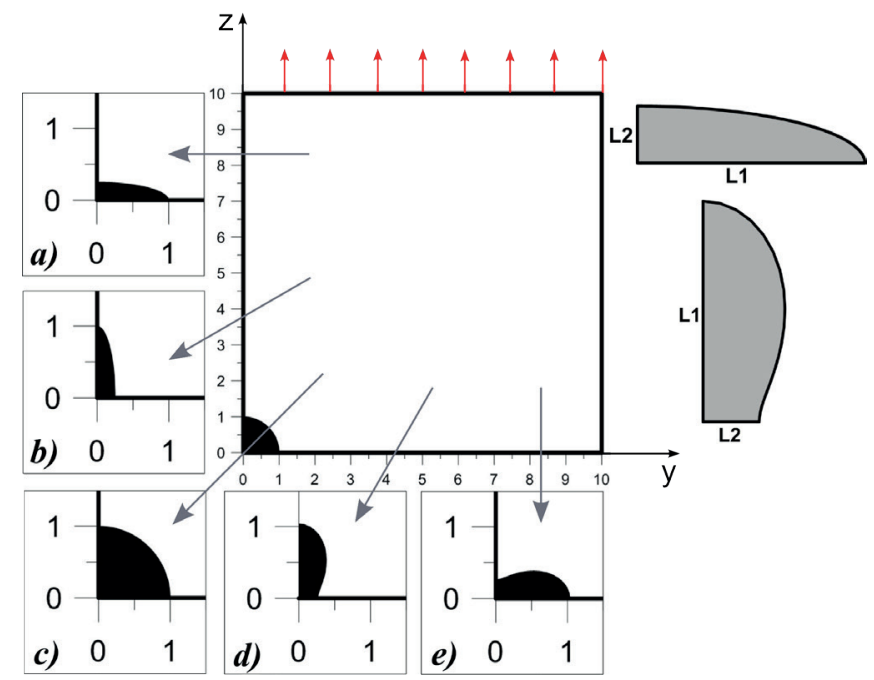

Fig. 5. Unit cell with various inclusion shapes

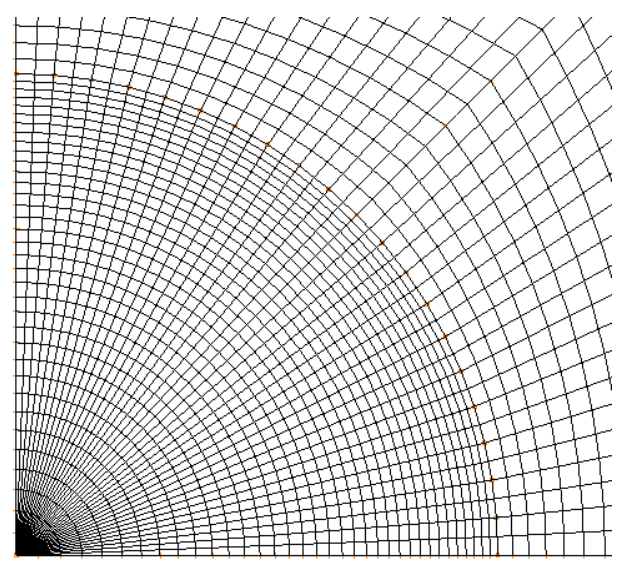

Fig. 6. FE mesh in and around the inclusions

\subsection{Results of numerical computation}

In Fig. 7, the opening stress distributions, $\sigma_{z z}$, along the horizontal and vertical axes are shown for various inclusion shapes and various loading conditions applied to the cell. Selected numerical results are shown in Tables 3-6.
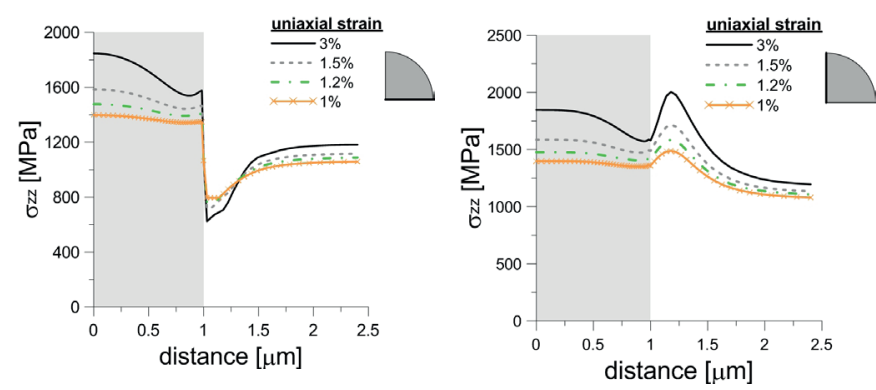

Fig. 7a. (Spherical inclusion.) ozz stress distribution along the horizontal line.
Fig. 7b. (Spherical inclusion.) $\sigma_{z z}$ stress distribution along the vertical line 


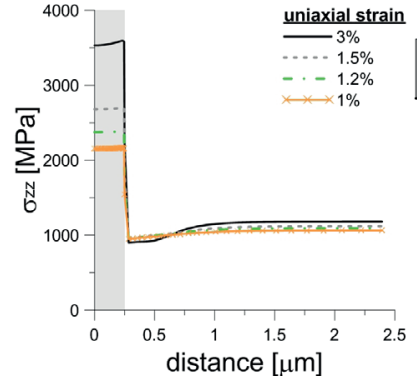

Fig. 7c. (Ellipsoidal inclusion with its major axis oriented parallel to the loading direction.) Opening stress $\left(\sigma_{z z}\right)$ distribution along the horizontal line.
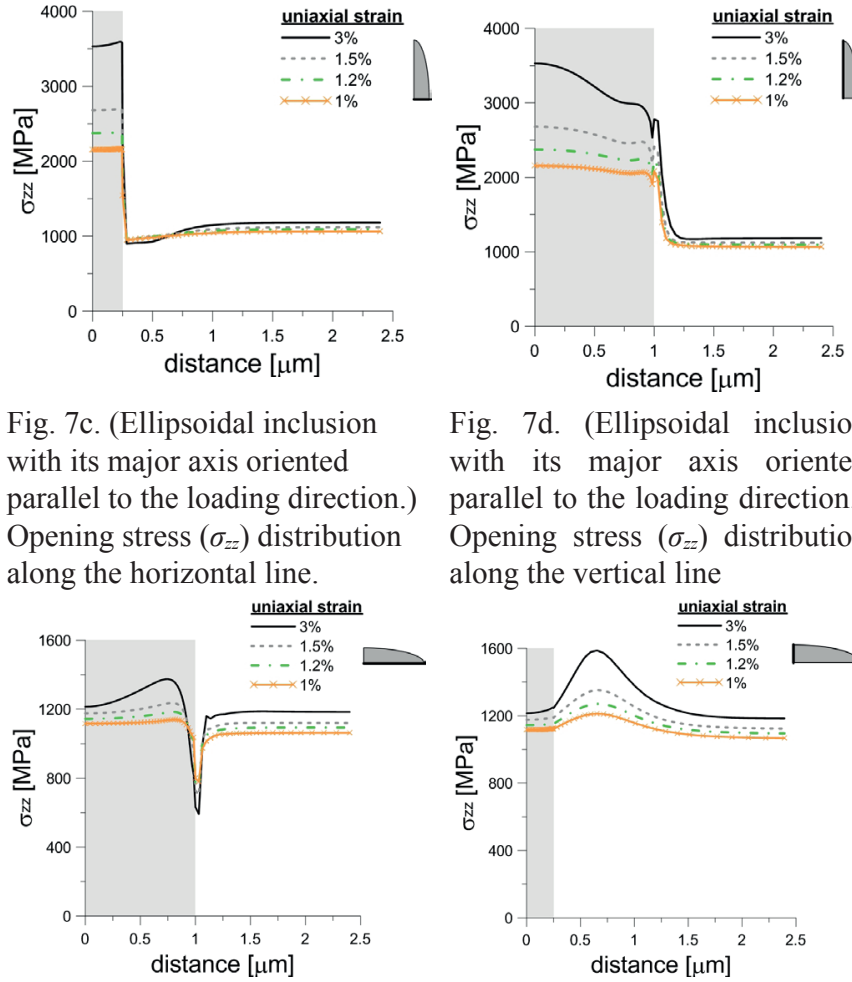

Fig. 7d. (Ellipsoidal inclusion with its major axis oriented parallel to the loading direction.) Opening stress $\left(\sigma_{z z}\right)$ distribution along the vertical line

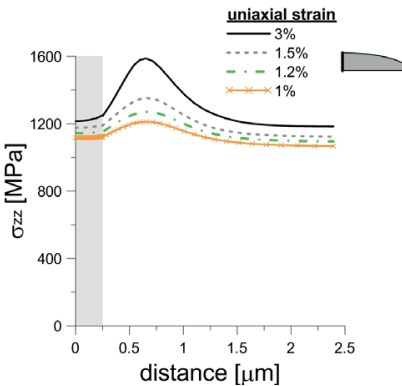

Fig. 7e. (Ellipsoidal inclusion Fig. 7f. (Ellipsoidal inclusion with its major axis oriented with the major axis oriented perpendicular to the loading perpendicular to the loading direction.) Opening stress $\left(\sigma_{z z}\right)$ direction.) Opening stress $\left(\sigma_{z z}\right)$ distribution along the horizontal distribution along the vertical line line.
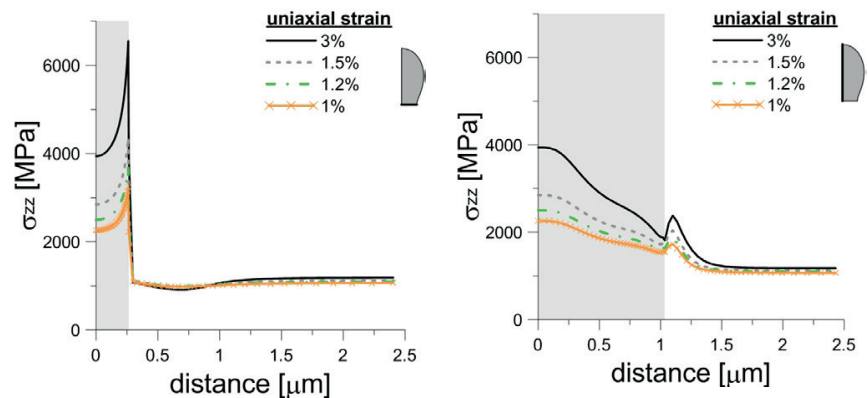

Fig. 7g. (Elongated inclusion (Fig. Fig. 7h. (Elongated inclusion 5d) with its longest axis oriented (Fig. 5d) with the longest axis parallel to the loading direction.) oriented parallel to the loading Opening stress $\left(\sigma_{z z}\right)$ distribution direction.) Opening stress $\left(\sigma_{z z}\right)$ along the horizontal line distribution along the vertical line
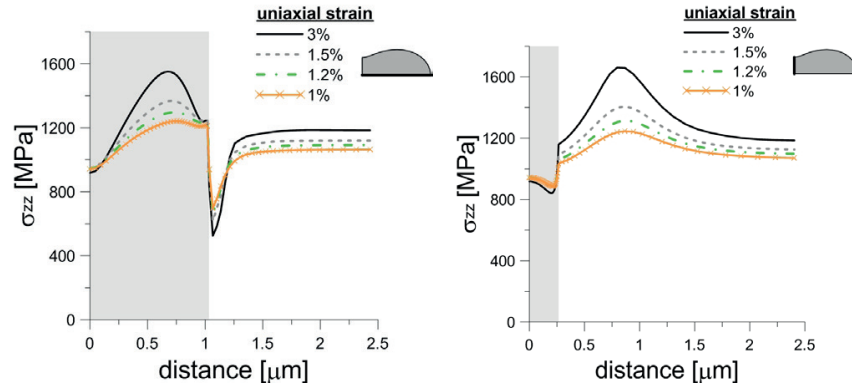

Fig. 7i. (Elongated inclusion (Fig. Fig. 7j. (Elongated inclusion (Fig. $5 \mathrm{e}$ ) with the longest axis oriented $5 \mathrm{e}$ ) with its longest axis oriented perpendicular to the loading perpendicular to the loading direction.) Opening stress $\left(\sigma_{z z}\right)$ direction.) Opening stress $\left(\sigma_{z z}\right)$ distribution along the horizontal distribution along the vertical line line

TABLE 3

Maximum opening and effective stresses $\left(\sigma_{e}=\sqrt{3 J_{2}}=\sqrt{\frac{3 s_{i j} s_{i j}}{2}}\right.$, where $J_{2}$ is the second invariant of the deviatoric stress) in and around

\begin{tabular}{|c|c|c|c|c|}
\hline $\begin{array}{c}\text { Loading } \\
\text { strain }\end{array}$ & $\begin{array}{c}\text { Max. opening } \\
\text { Stress inside } \\
\text { (effective stress) } \\
\text { Horizontal line } \\
\text { MPa } \\
\end{array}$ & $\begin{array}{l}\text { Max. opening } \\
\text { Stress outside } \\
\text { Horizontal line } \\
\qquad \mathrm{MPa}\end{array}$ & $\begin{array}{c}\text { Max. opening } \\
\text { Stress inside } \\
\text { (effective stress) } \\
\text { Vertical line } \\
\text { MPa } \\
\end{array}$ & $\begin{array}{c}\text { Max. opening } \\
\text { Stress outside } \\
\text { Vertical line } \\
\text { MPa }\end{array}$ \\
\hline $1 \%$ & $1400(1620)$ & 1060 & $1400(1620)$ & 1490 \\
\hline $1.2 \%$ & $1480(1749)$ & 1090 & $1480(1740)$ & 1580 \\
\hline $1.5 \%$ & $1590(1910)$ & 1120 & $1590(1910)$ & 1720 \\
\hline $3 \%$ & $1850(2300)$ & 1180 & $1850(2300)$ & 2000 \\
\hline
\end{tabular}

TABLE 4

Maximum opening and effective stresses in and around an elongated inclusion with the major axis oriented in the loading direction (Fig. 5d).

\begin{tabular}{|c|c|c|c|c|}
\hline \hline & $\begin{array}{c}\text { Max. opening } \\
\text { Ltress inside inclusion } \\
\text { Loading } \\
\text { strain }\end{array}$ & $\begin{array}{c}\text { Max. opening } \\
\text { Stress outside inclusion } \\
\text { Horizontal line } \\
\mathrm{MPa}\end{array}$ & $\begin{array}{c}\text { Max. opening } \\
\text { Stress inside inclusion } \\
\text { (effective stress) } \\
\text { Vertical line } \\
\mathrm{MPa}\end{array}$ & $\begin{array}{c}\text { Max. opening } \\
\text { Stress outside inclusion } \\
\text { Vertical line } \\
\text { MPa }\end{array}$ \\
\hline $1 \%$ & $\mathbf{3 2 3 9 ( 3 1 4 0 )}$ & 1060 & $\mathbf{2 2 6 0}$ & 1730 \\
\hline $1.2 \%$ & $\mathbf{3 6 8 0}(\mathbf{3 5 7 0})$ & 1090 & $\mathbf{2 5 0 0}$ & 1860 \\
\hline $1.5 \%$ & $\mathbf{4 3 5 0}(\mathbf{4 2 2 0})$ & 1120 & $\mathbf{2 8 5 0}$ & 2040 \\
\hline $3 \%$ & $\mathbf{6 5 5 5}(\mathbf{6 3 2 0})$ & 1180 & $\mathbf{3 9 4 0}$ & 2380 \\
\hline
\end{tabular}


TABLE 5

Maximum opening and effective stresses in and around an elongated inclusion with the longer axis oriented in direction perpendicular to loading (Fig. 5e)

\begin{tabular}{|c|c|c|c|c|}
\hline $\begin{array}{c}\text { Loading } \\
\text { strain }\end{array}$ & $\begin{array}{c}\text { Max. opening } \\
\text { Stress inside inclusion } \\
\text { (effective stress) } \\
\text { Horizontal line } \\
\mathrm{MPa} \\
\end{array}$ & $\begin{array}{c}\text { Max. opening } \\
\text { Stress outside inclusion } \\
\text { Horizontal line } \\
\mathrm{MPa}\end{array}$ & $\begin{array}{c}\text { Max. opening } \\
\text { Stress inside inclusion } \\
\text { (effective stress) } \\
\text { Vertical line } \\
\text { MPa }\end{array}$ & $\begin{array}{c}\text { Max. opening } \\
\text { Stress outside inclusion } \\
\text { Vertical line } \\
\mathrm{MPa}\end{array}$ \\
\hline $1 \%$ & $1240(1590)$ & 1060 & 942 & 1250 \\
\hline $1.2 \%$ & $1300(1710)$ & 1090 & 945 & 1310 \\
\hline $1.5 \%$ & $1370(1860)$ & 1120 & 945 & 1410 \\
\hline $3 \%$ & $1550(2220)$ & 1180 & 919 & 1660 \\
\hline
\end{tabular}

TABLE 6

Maximum opening and effective stresses in and around an ellipsoidal inclusion with the major axis oriented in the loading direction (Fig. 5b)

\begin{tabular}{|c|c|c|c|c|}
\hline $\begin{array}{c}\text { Loading } \\
\text { strain }\end{array}$ & $\begin{array}{c}\text { Max. opening } \\
\text { Stress inside inclusion } \\
\text { (effective stress) } \\
\text { Horizontal line } \\
\text { MPa }\end{array}$ & $\begin{array}{c}\text { Max. opening } \\
\text { Stress outside inclusion } \\
\text { Horizontal line } \\
\mathrm{MPa}\end{array}$ & $\begin{array}{c}\text { Max. opening } \\
\text { Stress inside inclusion } \\
\text { (effective stress) } \\
\text { Vertical line } \\
\mathrm{MPa}\end{array}$ & $\begin{array}{c}\text { Max. opening } \\
\text { Stress outside inclusion } \\
\text { Vertical line } \\
\mathrm{MPa}\end{array}$ \\
\hline $1 \%$ & $2160(2226)$ & 1060 & 2160 & 2080 \\
\hline $1.2 \%$ & $2380(2510)$ & 1090 & 2370 & 2240 \\
\hline $1.5 \%$ & $2700(2860)$ & 1120 & 2680 & 2480 \\
\hline $3 \%$ & $3590(3890)$ & 1180 & 3530 & 2780 \\
\hline
\end{tabular}

Fig. 8 shows the selected example of the accumulated effective plastic strain distribution along the line perpendicular and external to the inclusion surface. The line starts from the surface.

Fig. 9 shows the selected example of the stress distribution within an inclusion containing a small crack-like defect. Defect is located at the inclusion centre; its size was $0.2 \mu \mathrm{m}$.
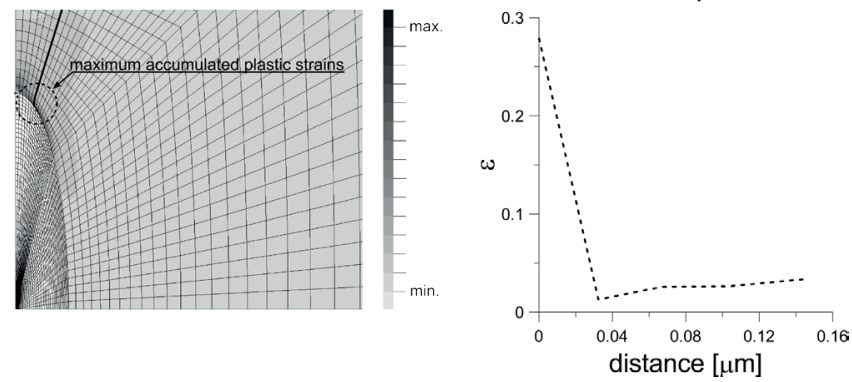

Fig. 8a. Effective accumulated Fig. 8b. Effective accumulated plastic strain maximum
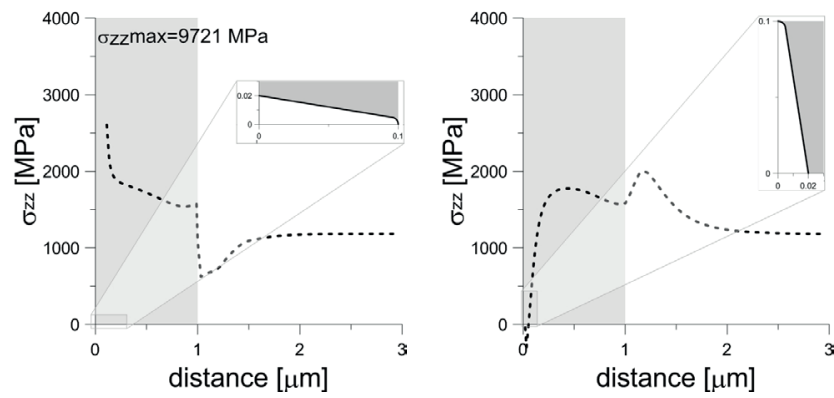

Fig. 9a. Opening stress $\left(\sigma_{z z}\right)$ Fig. 9b. Opening stress $\left(\sigma_{z z}\right)$ distribution along the horizontal distribution along the vertical line in the spherical inclusion, line in the spherical inclusion, next to the micro-crack
Fig. 10 shows the stress distribution in and around a spherical inclusion more compliant $(E=120000 \mathrm{MPa})$ than the matrix.
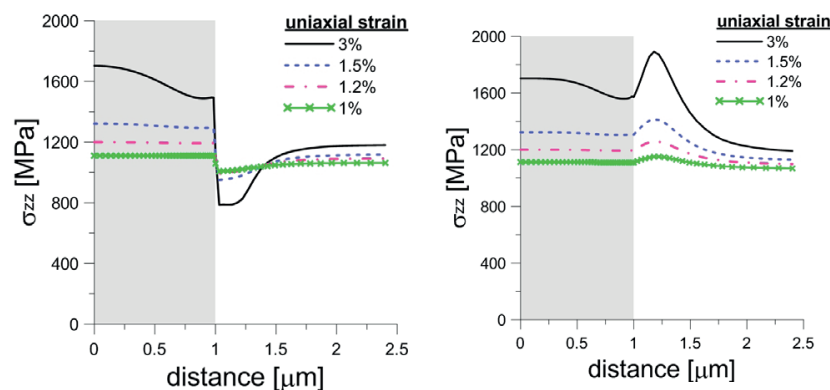

Fig. 10a. (Spherical inclusion.) Fig. 10b. (Spherical inclusion.) Opening stress $\left(\sigma_{z z}\right)$ distribution Opening stress $\left(\sigma_{z z}\right)$ distribution along the horizontal line. along the vertical line. Young's Young's modulus: $120 \mathrm{GPa}$ modulus: $120 \mathrm{GPa}$

\section{Discussion and conclusions}

The opening stress level calculated by numerical analysis, when compared with microscopic observations, allows a rough estimation of the critical stress necessary to fracture an inclusion. Structural materials contain a variety of inclusions. Within the Hardox-400 steel, we observed: titanium nitrides, manganese sulphides, magnesium oxides, aluminium oxides and other compounds of calcium and ferrite. Some of them, such as the titanium nitrides, had cuboidal shape and usually had a uniform structure. In such cases, they fractured in the strain range of $1.2 \%-1.25 \%$. However, when the TiN inclusions nucleated around some other phase (Fig. 4b) they had already fractured at the $1 \%$ strain level because of the local stress concentration. Uniform manganese sulphides were observed at 
an overall strain of $1.5 \%$ (Fig. 3a). Beremin [14] proposed that the critical opening stress for this material is approximately $1100 \mathrm{MPa}$. From our observations and computations we would suggest a higher value, perhaps $1400 \mathrm{MPa}$. In Tables 3-6 the shadowed fields indicate that the opening stress was greater than the critical value. We assumed for this purpose a critical value of approximately $1600 \mathrm{MPa}$ for TiN. (Shabrov et al. [9] proposed the value of $2300 \mathrm{MPa}$ for TiN in 4340 steel, and Alexandre et al. [15] proposed values between 1280 to 1540 $\mathrm{MPa}$ in Inconel 718).

It should be noted that the shape of the inclusion plays a fundamental role in the stress level and the onset of void nucleation. However, the MnS particles usually exhibited a complex morphology. When they were mixed with other phases (see Figs 3b, 3d, 4d) they fractured at much smaller values of overall strain (i.e., $0.9 \%-1,5 \%$ ); microscopic observations do not allow for precise estimation of the critical stress. Scanning electron microscopy observations, even when preceded by careful mechanical polishing, do not always allow for unequivocal conclusions about the mechanisms of void nucleation, leaving the question: is it due to inclusion fracture or due to debonding? In this context, Beremin proposed that the critical stress for debonding a $\mathrm{MnS}$ particle is $800 \mathrm{MPa}$, a much lower value than that required to fracture such an inclusion. We did not observe many sites where debonding could had taken place. The cavities we did observe at $1 \%$ uniaxial strain could have arisen from the polishing process or the fracture of non-uniform inclusions. In most cases, what we observed was probably inclusion fracture.

We did not observe any difference in the stress distributions and the levels of the stresses computed for large (i.e., $2 \mu \mathrm{m}$ ) and small (i.e., $0.4 \mu \mathrm{m}$ ) inclusions. Thus, the observation that the small inclusions are debonded from the matrix whereas the large inclusions fracture could be explained by assuming that the likelihood of finding a sub-micro crack inside a large inclusion is much higher than in a small one. These small cracks raise the stress inside the inclusions to very high levels (see Fig. 9).

There prevails an opinion that the debonding process takes place because of the very high and non-uniform plastic strain distribution. In Fig. 8 we present evidence of accumulated effective plastic strain distribution. The location of the highest strain values and the largest strain gradients is shown. The location of this area is similar in other inclusion geometries. One would expect that debonding could take place at this site. However, numerical modelling by Galkiewicz [19] using the cohesive model suggests other locations of debonding initiation.

In our scanning electron microscopy observations, we did not observe any signs of matrix fracture next to the inclusions. In another report [20], the critical stress for Hardox-400 steel was estimated to be $3200 \mathrm{MPa}$. This level of stress was never reached in our numerical analysis. However, it should be noted that at the moment an inclusion fractures, the stress distribution around the newly initiated micro-crack changes suddenly. This is the subject of our next analysis.

\section{Acknowledgements}

Financial support from the Polish Centre of Science under contract No. 2014/15/B/ST8/00205 is gratefully acknowledged.

\section{REFERENCES}

[1] A. Pineau, T. Pardoen, Failure of metals, in Comprehensive Structural Integrity, Fundamental Theories and Mechanisms of Failure, Science Direct, vol. 2, 684-783, (2007).

[2] J. H. Chen, R. Cao, Micromechanism of cleavage fracture of metals, Elsevier, 2015.

[3] J. Besson, editor, Local approach to fracture, Ecole des Mines de Paris, 2004.

[4] M. F. Horstemeyer, S. Ramaswamy, M. Negrete, Mechanics of Materials 35, 675-687, (2003).

[5] A. S. Gullerud, X. Gao, R. H. Jr. Dodds, R. Haj-Ali, Engineering Fracture Mechanics 66, 65-92, (2000).

[6] J. Gurland, Acta Metallurgica 20, 735-741, (1972).

[7] M. D. Dighe, A. M. Gokhale, M. F. Horstemeyer, Metallurgical and Materials Transactions A 33, 1-8, (2002).

[8] M. N. Shabrov, A. Needleman, Modelling and Simulation in Materials Science and Engineering 10, 163-183, (2002).

[9] M. N. Shabrov, E. Sylven, S. Kim, D. H. Sherman, L. Chuzhoy, C. L. Briant, A. Needleman, Metallurgical and Materials Transactions A 35, 1745-1755, (2004).

[10] A. S. Argon, J. Im, Metallurgical and Materials Transactions A 6, 839-851, (1975).

[11] A. Needleman, A continuum model for void nucleation by inclusion debonding, Journal of Applied Mechanics 54, 525531, (1987).

[12] J. D. Eshelby, Proc. R. Soc. A 241, 376-396, (1957).

[13] B. Z. Margolin, A. G. Gulenko, V. A. Shvetsova, Int. J. Pressure Vessels Piping 75, 843-855, (1998).

[14] F. M. Beremin, Materials Transactions A 12, 723-731, (1981).

[15] F. Alexandre, S. Deyber, J. Vaissaud, A. Pineau, TMS, The Minerals, Metals and Materials Society, Superalloys, 02-05 October, (2005)

[16] G. Huber, Y. Brechet, T. Pardoen, Acta Materialia 53, 2739 2749, (2005).

[17] A. Needleman, J. Mech. Phys. Solids 38, 289-324, (1990).

[18] A. Neimitz, I. Dzioba, R. Pała, U. Janus, Solid State Phenomena, Trans Tech Publications, 224, 157-166, (2015).

[19] J. Galkiewicz, Kielce University of Technology, private communication.

[20] A. Neimitz, I. Dzioba, U. Janus, Key Engineering Materials, Trans Tech. Publications 598, 168-177, (2014). 
